\title{
Controls of Strontium and Lithium Isotope Spatial Variability across the Yukon River Basin
}

\author{
MyUnhGAK KANG ${ }^{1 *}$, SeAn R. BRENNAN ${ }^{2}$, Clement P. \\ BATAILLE ${ }^{1}$ \\ ${ }^{1}$ Department of Earth and Environmental Sciences, University \\ of Ottawa, Ottawa, ON, K1N 6N5, Canada; \\ ${ }^{2}$ School of Aquatic and Fishery Sciences, University of \\ Washington, Seattle, WA, 98105, USA; \\ *mkang059@uottawa.ca
}

The Yukon River drains a large catchment underlain by a range of geological units and characterized by diverse topography, environmental conditions, and land cover. The Yukon River catchment also displays a gradient of permafrost cover and has active alpine glaciers in its headwaters. With on-going warming, permafrost degradation, glaciers retreat, land cover changes and climate variations are likely influencing the hydrochemistry of the Yukon River with risks for water quality and ecosystem sustainability. Here, we report elemental and isotopic data across the Yukon River to unravel the processes and sources controlling the geochemistry of the dissolved load across the watershed and investigate the sensitivity of hydrochemistry to climate conditions.

We analyze 120 samples from most major tributaries of the Yukon River for major and trace elements, strontium isotope ratio $\left({ }^{87} \mathrm{Sr} /{ }^{86} \mathrm{Sr}\right)$ and lithium isotope composition $\left(\delta^{7} \mathrm{Li}\right)$. Elemental and isotopic geochemistry displays strong spatial patterns that primarily correlate with lithological distribution over the watershed. In the glacial and mountainous headwaters, we observe elevated weathering rate, low $\mathrm{Li} / \mathrm{Na}$ ratio and low $\delta^{7} \mathrm{Li}$ values $(<15 \%)$. We suggest that glaciated headwaters are characterized by a very high denudation rate and low secondary mineral formation rate. In most of the lowlands glaciated or not, we observe relatively constant $\mathrm{Li} / \mathrm{Na}$ ratio and $\delta^{7} \mathrm{Li}$ values $(\sim 19 \%)$, suggesting that weathering intensity is at steadystate. In the lowlands, ${ }^{87} \mathrm{Sr} /{ }^{86} \mathrm{Sr}$ ratios also remain within a tight range of values (0.709-0.715) and reflect the variable contribution of carbonate and silicate units. $\delta^{7} \mathrm{Li}$ values are very high $(>25 \%$ o $)$ and ${ }^{87} \mathrm{Sr} /{ }^{86} \mathrm{Sr}$ very low $(<0.707)$ in all the tributaries draining volcanic units of the Chugach terrane. We interpret these trends as reflecting a high secondary mineral formation rates in this volcanic setting. Lastly, $\delta^{7} \mathrm{Li}$ values are highest in the streams draining the old and radiogenic rocks of the Yukon Tanana terrane, possibly due to high groundwater flow in those regions. Overall, most of the elemental and isotopic variability across the Yukon River is explained by geological controls with limited influence of glacial processes. 